\title{
Middle aortic syndrome treated by stent implantation
}

G Brzezinska-Rajszys, S A Qureshi, J Ksiazyk, M Zubrzycka, A Kosciesza, K Kubicka, M Tynan

\begin{abstract}
Objectives-To determine outcome of stent implantation in patients with middle aortic syndrome.

Design-Prospective study, case series. Setting-A tertiary paediatric cardiology centre in a children's hospital.

Patients-Five patients, aged 4 to 17 years (mean 11.4 years), with upper limb hypertension due to middle aortic syndrome.

Intervention-Stents were implanted in the mid/lower thoracic/upper abdominal aorta.
\end{abstract}

Main outcome measure-Satisfactory deployment of stents and blood pressure control.

Results-In all patients, angiocardiography showed long segment stenosis in the mid or lower thoracic/upper abdominal aorta. The pressure gradient was between 40 and $90 \mathrm{~mm} \mathrm{Hg}$ (mean $63.2 \mathrm{~mm} \mathrm{Hg}$ ). Seven Palmaz stents were implanted. Immediately after implantation, the gradient decreased to between 0 and 35 mm Hg (mean $13.6 \mathrm{~mm} \mathrm{Hg}$ ). Angiography showed a satisfactory result with widely patent stents in all. In one patient, thrombosis of the stent occurred six days after implantation. This was successfully treated with infusion of alteplase, further balloon dilatation, and implantation of a second stent overlapping the first, both dilated to $10 \mathrm{~mm}$ diameter. One patient had elective redilatation of the stent six months after implantation, with further reduction of the gradient from $35 \mathrm{~mm} \mathrm{Hg}$ to $10 \mathrm{~mm} \mathrm{Hg}$. At the latest follow up between three and 20 months (mean 12.2 months) after stent implantation, in four patients blood pressure was better controlled with antihypertensive drugs. One patient was normotensive without drugs. Computed tomography showed no aneurysm formation in the region of the stents. Conclusions-Stent implantation is a preferable alternative to surgery in the treatment of patients with middle aortic syndrome and merits further evaluation. (Heart 1999;81:166-170)

Keywords: middle aortic syndrome; stent implantation; paediatric cardiology; interventional cardiology

Middle aortic syndrome is an uncommon cause of upper limb hypertension. The clinical features may be similar to those of aortic coarctation, with upper limb hypertension and weak or absent femoral pulses, but the echocardiogram may not show coarctation at the usual site. In such patients, a localised, discrete, or long hypoplastic segment coarctation may be evident in the lower thoracic or upper abdominal aorta on magnetic resonance imaging or aortography. This disease has been named "middle aortic syndrome." When a long segment hypoplasia occurs in this region, the treatment may be difficult. ${ }^{23}$ The treatment may consist of either attempts at balloon dilatation or surgical conduit bypass. ${ }^{34}$ While the surgical bypass presents technical difficulties in children, non-surgical treatment is not easy as the hypoplastic segment may or may not be amenable to balloon dilatation. ${ }^{2}{ }^{4}$

Balloon dilatation in aortic coarctation or recoarctation is successful in over $70 \%$ of cases, but the major determinant of success is the arch anatomy..$^{5-7}$ There is a significant incidence of aneurysm formation, full thickness tears, and even death. Stent implantation may overcome some, if not all, of these complications. Stents have been used in various congenital heart defects, such as branch pulmonary artery stenosis, vena caval stenosis, and aortic recoarctation, ${ }^{89}$ in which balloon dilatation alone may produce unpredictable or unsatisfactory results. ${ }^{5-7}$ The application of stents has continued to widen. However, they have disadvantages in patients who have not reached their full growth.

We attempted stent implantation in five patients with middle aortic syndrome and present the early results and their outcome.

\section{Methods}

PATIENTS

Five patients, aged between 4 and 17 years, mean 11.4 years, presented with upper limb hypertension, weak femoral pulses, and an audible systolic murmur over the back and precordium. The hypertension had been controlled with nifedipine and captopril in three patients, with labetalol and nifedipine in one, and with nifedipine alone in one. One patient (case 5), aged 4 years, had had a left thoracotomy because of a presumed diagnosis of a classic aortic coarctation.

\section{INVESTIGATIONS}

In all patients, cardiac catheterisation and angiography was performed under general anaesthesia by the femoral artery route using a $5 \mathrm{~F}$ or $6 \mathrm{~F}$ angiographic catheter. The clinical and haemodynamic data are given in table 1 . The pressure gradient across the stenosis was 
Table 1 Procedure details

\begin{tabular}{|c|c|c|c|c|c|}
\hline & Patient 1 & Patient 2 & Patient 3 & Patient 4 & Patient 5 \\
\hline Age (years) & 13 & 15 & 17 & 8 & 4 \\
\hline Weight $(\mathrm{kg})$ & 59 & 54 & 64 & 20 & 15 \\
\hline Minimum diameter of stenosis (mm) & 3.5 & 5 & 3.7 & 2.5 & 2.5 \\
\hline Length of stenosis $(\mathrm{cm})$ & 5.5 & 8.3 & 4.2 & 3.5 & 4 \\
\hline Dimension of normal aorta proximal to stenosis (mm) & 12 & 16 & 12 & 10 & 7 \\
\hline Pressure proximal to stenosis before stent implantation $(\mathrm{mm} \mathrm{Hg})$ & $160 / 110$ & $186 / 120$ & $120 / 70$ & $100 / 70$ & $170 / 80$ \\
\hline Pressure distal to stenosis before stent implantation ( $\mathrm{mm} \mathrm{Hg}$ ) & $100 / 90$ & $120 / 90$ & $72 / 60$ & $60 / 55$ & $80 / 60$ \\
\hline Gradient across stenosis before stent implantation (mm Hg) & 60 & 65 & 50 & 40 & 90 \\
\hline Final stent diameter $(\mathrm{mm})$ & 6 & 10 & 8 & 8 & 7 \\
\hline Pressure proximal to stenosis after stent implantation $(\mathrm{mm} \mathrm{Hg})$ & $125 / 100$ & $110 / 6$ & $130 / 80$ & $120 / 70$ & $100 / 70$ \\
\hline Pressure distal to stenosis after stent implantation $(\mathrm{mm} \mathrm{Hg})$ & $112 / 90$ & $102 / 66$ & $95 / 75$ & $120 / 70$ & $90 / 70$ \\
\hline Gradient across stenosis after stent implantation (mm Hg) & 15 & 8 & 35 & 0 & 10 \\
\hline Type and number of stents used & $\begin{array}{l}1 \times 5014,1 \times 4014 \\
\text { (after thrombolytic } \\
\text { treatment) }\end{array}$ & $1 \times 5014,1 \times 4014$ & $1 \times 5014$ & $1 \times 308$ & $1 \times 4014$ \\
\hline
\end{tabular}

between 40 and $90 \mathrm{~mm} \mathrm{Hg}$ (mean 63.2 $\mathrm{mm} \mathrm{Hg}$ ). Angiography confirmed long segment stenosis in the mid or lower thoracic or upper abdominal aorta. The minimum diameter of the stenosis was between $2.5 \mathrm{~mm}$ and $5.0 \mathrm{~mm}$ and the length of the stenosis ranged between $3.5 \mathrm{~cm}$ and $8.3 \mathrm{~cm}$. One patient (case 4 ), aged 8 years, had additional stenosis of the right renal artery and underwent successful balloon angioplasty of the stenotic artery immediately before stent implantation.

\section{STENT IMPLANTATION}

An $11 \mathrm{~F}$ transeptal sheath was inserted into the femoral artery in the three older patients and the carotid artery cut down approach was used in the remaining two, in whom $8 \mathrm{~F}$ sheaths were inserted. The carotid artery cut down approach was used in these two because of their small age and size for the insertion of an $8 \mathrm{~F}$ sheath in the femoral artery. The sheaths were positioned just distal to the stenosis. In four patients, the stents were mounted on Olbert balloons (Meditech Boston Scientific
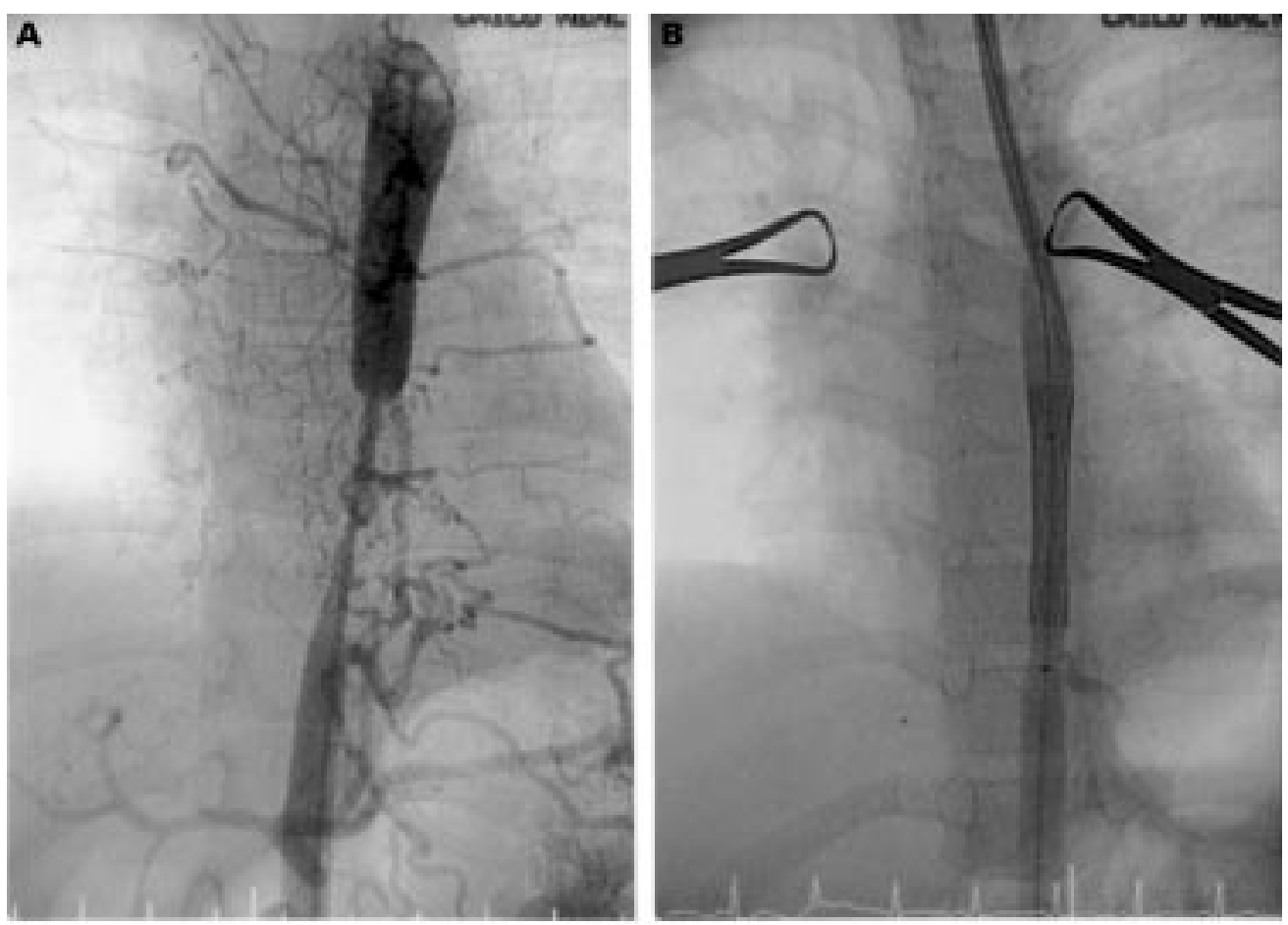

Corporation, Watertown, Massachusetts, USA) of $8-10 \mathrm{~mm}$ diameter and $4 \mathrm{~cm}$ length, and in one patient the stent was mounted on Powerflex balloon (Cordis Europe, Roden, the Netherlands) of $7 \mathrm{~mm}$ diameter and $4 \mathrm{~cm}$ length. Three Palmaz 5014, two Palmaz 4014, and one Palmaz 308 stents (Johnson and Johnson Intervention Systems, Warren, New Jersey, USA) were used at the initial procedure. The stent/balloon assembly was advanced through the sheath and positioned at the level of the stenosis. After withdrawal of the sheath, the balloon was gradually inflated to its nominal diameter up to a pressure of 10-20 atmospheres. Because gradual progressive dilatation over a period of several years was planned, the stents were not electively dilated to the diameter of the normal aorta above or below the stenosis. In one patient (case 2), the fully expanded stent did not cover the entire length of the stenosis and so a second Palmaz 4014 stent was placed overlapping the first Palmaz 5014 stent (table 1 ).

Figure 1 (A) Aortogram in patient 5 showing a long segment stenosis of the thoracic aorta. (B) Aortogram after stent implantation. 

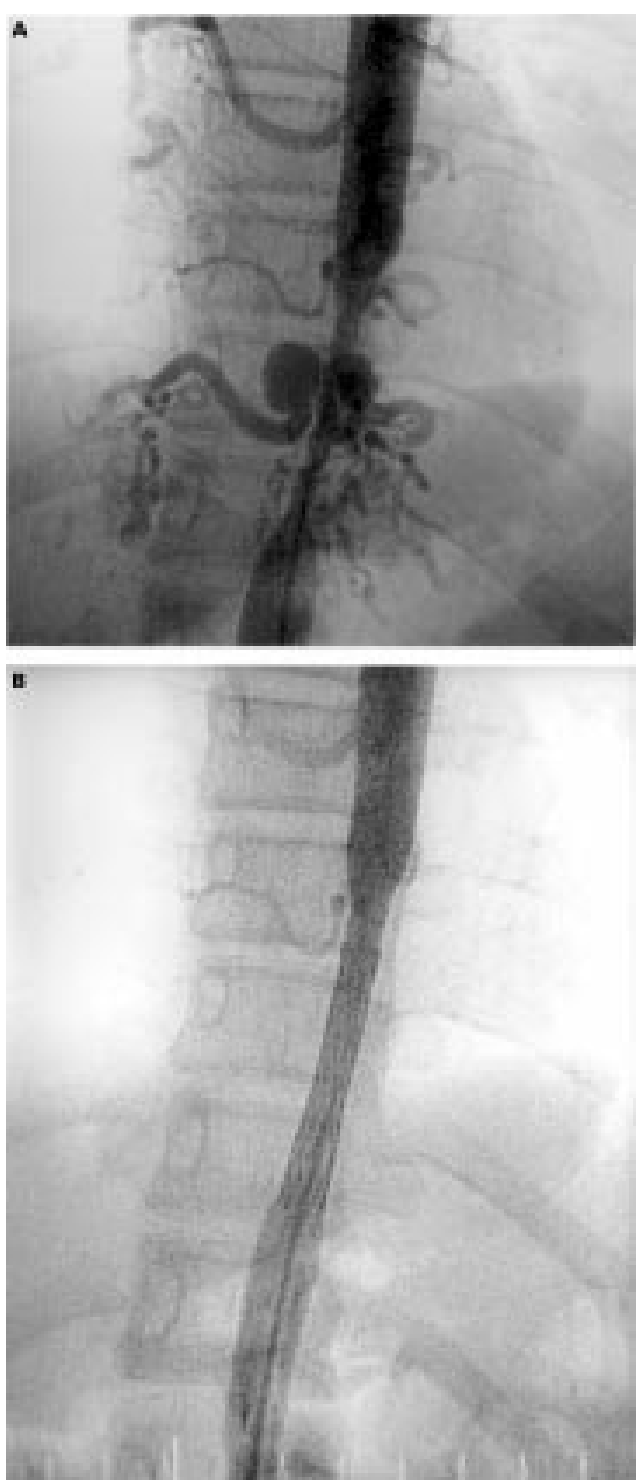

Figure 2 (A) Aortogram in patient 1 showing long segment stenosis in the thoracic aorta with collaterals. (B) Aortogram after stent implantation.

After the procedure, the patients were maintained on heparin for 48 hours and aspirin and anticoagulants (Sinthrome; Novarks, Surrey, UK) for three months. The antihypertensive treatment was also maintained after the procedure.

\section{Results}

Immediately after stent implantation, the residual gradient ranged between 0 and 35 $\mathrm{mm} \mathrm{Hg}$ (mean $13.6 \mathrm{~mm} \mathrm{Hg}$ ) and there was a decrease in the aortic pressure above the stenosis in three of the five patients. Angiography showed a satisfactory result with widely patent (fig 1) and correctly positioned stents in all patients.

An important complication occurred in only one patient; thrombosis of the stent occurred six days after implantation (case 1). This was successfully treated with an infusion of alteplase (recombinant human tissue-type plasminogen activator) for three days. In this patient, at the time of the initial stent implantation the balloon had ruptured during inflation before full expansion (fig 2). Further inflation was not attempted. After thrombolytic treatment had shown recanalisation, additional balloon dilatation was performed, followed immediately by the implantation of a second stent overlapping the first, both of which were dilated to $10 \mathrm{~mm}$ diameter (fig 3). At the time of the investigation for suspected thrombosis and placement of catheters for the infusion of alteplase, manipulation of catheters and guidewires resulted in a dissection and small aneurysm of the distal part of the aorta, below the renal arteries and below the stents, which has been treated conservatively.

During the follow up period, varying between three and 20 months, blood pressure was well controlled with the previous treatment in four patients. Antihypertensive treatment has been withdrawn successfully in one patient after stent implantation. The femoral arterial pulses were easily palpable in all patients. Computed tomography showed no aneurysm formation in relation to the stents. In the patient in whom the first stent had thrombosed and another inserted, and in whom a dissection/aneurysm below the stents had been noted, at follow up 14 months later, the blood pressure was controlled with the previous drug regimen and computed tomography showed a small aneurysm at the site of the dissection but none in relation to the stent. One patient (case 3) had elective redilatation of the stent six months after implantation. This resulted in a further reduction of the gradient from 35 $\mathrm{mm} \mathrm{Hg}$ to $10 \mathrm{~mm} \mathrm{Hg}$.

In all patients spiral computed tomography, performed three to 12 months after stent implantation, confirmed satisfactory anatomical results.

\section{Discussion}

Balloon dilatation is considered an acceptable alternative treatment to surgery in patients with aortic recoarctation. ${ }^{5}$ It produces satisfactory results in over $70 \%$ of the patients. However, there is a small risk of aneurysm formation. ${ }^{10}$ The anatomy of the aortic arch is usually important in determining the results. Although balloon dilatation of native aortic coarctation has its proponents, ${ }^{311}$ it is not universally accepted and may be considered a controversial or investigational alternative to surgery. The complications of balloon dilatation, both of native coarctation and recoarctation, include acute aneurysm formation, dissection of the aorta, pseudoaneurysm, and even rupture of the aorta leading to death. ${ }^{512}{ }^{13}$ Intimal tears are an inherent part of the mechanism of balloon dilatation and cannot be controlled. In experimental balloon dilatation of excised specimens of aortic coarctation, tears in the vessel wall were present in all the specimens and histologically these tears extended to the intimal and medial layers. ${ }^{14}$ These histological findings were confirmed by several studies in both animal models of aortic coarctation as well as in patients who were evaluated by intravascular ultrasound before 

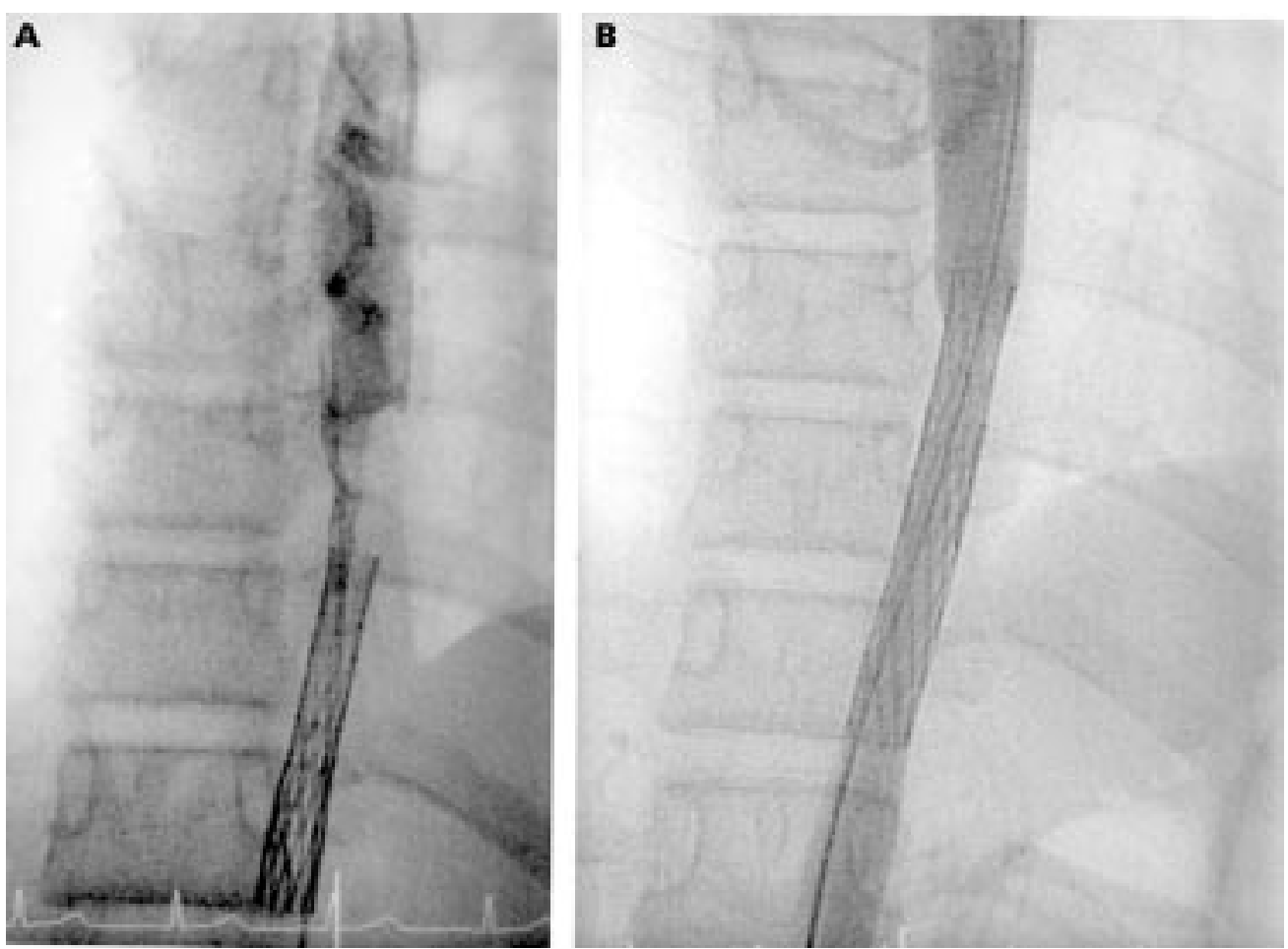

Figure 3 (A) Aortogram in patient 1 six days after the initial stent implantation showing extensive thrombosis of the stent and the aorta above the stent. (B) Aortogram after thrombolytic treatment and implantation of a further stent.

and after balloon dilatation of aortic coarctation. ${ }^{15-18}$ Intravascular ultrasound appears to be more sensitive than angiography in detecting vascular wall changes, and during the follow up evaluation the tears in the intima may decrease and not progress to aneurysms. ${ }^{18}$ Stent implantation, certainly in aortic recoarctation and possibly in native coarctation, may be a better alternative to balloon dilatation and its role is currently being evaluated. ${ }^{89}{ }^{19}$ Stents have the advantage of avoiding overdilatation of the stenotic segment and thus the extent of intimal injury may be more limited. Dilatation of the vessel by stents is thus more controlled and predictable and recoil of the stenotic lesion is avoided. Experimental studies have shown that neointimal formation occurred wherever the stent was in contact with the aortic wall and there was no significant intimal or medial injury. ${ }^{19}$ Furthermore, stents can be redilated after the patient has grown. ${ }^{19} 20$

Middle aortic syndrome is a difficult clinical problem to deal with. It is an uncommon cause of upper limb hypertension and is often detected during the investigation of hypertension. ${ }^{21}$ While it occurs as an isolated abnormality, it may be associated with neurofibromatosis, eosinophilia, Williams' syndrome, Takayasu's arteritis, and additional renal artery stenosis. ${ }^{42}$ Balloon dilatation has been attempted with some success on occasions, but the results may be unpredictable and unsatisfactory. ${ }^{2423}$ The mechanism of balloon dilatation is similar to dilatation of coarctation and tears may be seen on intravascular ultrasound. ${ }^{23}$ Surgical bypass using conduits is difficult and complicated and the tube graft may need to be replaced at a later date, especially if the patient has not reached full growth at the time of the initial surgical treatment. The type of surgery may involve thoracoabdominal to infrarenal aortic bypass with renal artery reimplantation, splenorenal bypass, aortorenal bypass, and autotransplantation. $^{4}$

In our limited initial experience, stent implantation has been attempted in five patients with middle aortic syndrome. In all patients, the stents were dilated electively to less than their optimal size and less than the size of the normal aorta on either side of the stenosis in an attempt to avoid overdilatation. The lumen diameter was between 2.5 and 5 $\mathrm{mm}$ and thus the vessel size was approximately doubled by the implanted stent. However, as a result of this approach, in one patient thrombosis of the stent occurred six days after implantation. In this patient, because of balloon rupture a suboptimal expansion of the stent had been accepted. Within a week, further balloon dilatation and implantation of another stent improved the result. We believe that gradual progressive dilatation over a period of a few months or even years, especially when keeping pace with the growth of the patient, would allow the intimal injury to heal before the next dilatation. In one patient, elective redilatation of the stent was successfully performed six months after implantation. This tends to support our clinical experience and that of other studies, suggesting that stents can be redilated even when completely covered with neointima. ${ }^{20}$

Stent implantation in the treatment of patients with middle aortic syndrome is less invasive than surgery, produces satisfactory early results, and merits further evaluation. 
1 Sumboonnanonda A, Robinson BL, Gedroyc WM, et al. Middle aortic syndrome: clinical and radiological findings. Middle aortic syndrome: clinical

2 Sievert H, Bussmann WD, Klepzig H, et al. Coarctation of the abdominal aorta. Experiences with transluminal angioplasty [in German]. Deutsche Med Wochenschr 1987; 112:1536-8.

3 Rao PS, Chopra PS. Role of balloon angioplasty in the treatment of aortic coarctation. Ann Thorac Surg 1991;52 621-31.

4 Panayiotopoulos YP, Tyrrell MR, Koffman G, et al. Mid-aortic syndrome presenting in childhood. Br f Surg 1996;83:235-40.

5 Anjos R, Qureshi SA, Rosenthal E, et al. Determinants of hemodynamic results of balloon dilation of aortic recoarctation. Am F Cardiol 1992;69:665-71.

6 Fawzy ME, Dunn B, Galal O, et al. Balloon coarctation angioplasty in adolescents and adults: early and intermedi-

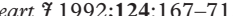

7 Schrader R, Bussmann WD, Jacobi V, et al. Long-term effects of balloon coarctation angioplasty on arterial blood pressure in adolescent and adult patients. Cathet Cardiovasc Diagn 1995;36:220-5.

8 Rosenthal E, Qureshi SA, Tynan M. Stent implantation for aortic recoarctation. Am Heart f 1995;129:1220-1.

9 Suarez de Lezo J, Pan M, Romero M, et al. Balloonexpandable stent repair of severe coarctation of aorta. $A m$ Heart f 1995;129:1002-8.

10 Joyce DH, McGrath LB. Pseudo-aneurysm formation following balloon angioplasty for recurrent coarctation of the aorta. Cathet Cardiovasc Diagn 1990;20:133-5.

11 Morrow WR, Vick GW, Nihill MR, et al. Balloon dilation of unoperated coarctation of the aorta: short- and intermediate-term results. f Am Coll Cardiol 1988;11:1338.

12 Krabill KA, Bass JL, Lucas RV, et al. Dissecting transverse aortic arch aneurysm after percutaneous transluminal balloon dilation angioplasty of an aortic coarctation. Pediatr loon dilation angioplasty
13 Huggon IC, Murdoch IA, Cooke AC, et al. Acute pseudoaneurysm formation complicating balloon dilation of native coarctation: treatment by delayed surgical repair. Pediatr Cardiol 1994;15:313-15.

14 Ho SY, Somerville J, Yip WC, et al. Transluminal balloon dilation of resected coarcted segments of thoracic aorta: histological study and clinical implications. Int $\mathcal{f}$ Cardiol 1988;19:99-105.

15 Rothman A, Ricou F, Weintraub RG, et al. Intraluminal ultrasound imaging through a balloon dilation catheter in an animal model of coarctation of the aorta. Circulation 1992;85:2291-5.

16 Stock JH, Reller MD, Sharma S, et al. Transballoon intravascular ultrasound imaging during balloon angioplasty in animal models with coarctation and branch pulmonary stenosis. Circulation 1997;95:2354-7.

17 Tong AD, Rothman A, Atkinson RL, et al. Intravascular ultrasound imaging of coarctation of the aorta: animal and human studies. Am f Cardiac Imaging 1995;9:250-6.

18 Sohn S, Rothman A, Shiota T, et al. Acute and follow-up intravascular ultrasound findings after balloon dilation of coarctation of the aorta. Circulation 1994;90:340-7.

19 Morrow WR, Smith VC, Ehler WJ, et al. Balloon angioplasty with stent implantation in experimental coarctation of the aorta. Circulation 1994;89:2677-83.

20 Morrow WR, Palmaz JC, Tio FO, et al. Re-expansion of balloon-expandable stents after growth. $\mathcal{F} \mathrm{Am}$ Coll Cardiol 1993;22:2007-13.

21 Robinson L, Gedroyc W, Reidy J, et al. Renal artery stenosis in children. Clin Radiol 1991;44:376-82.

22 Pagni S, Denatale RW, Boltax RS. Takayasu's arteritis: the middle aortic syndrome. Am Surg 1996;62:409-12.

23 Kashani IA, Sklansky MS, Movahed H, et al. Successful balloon dilation of an abdominal coarctation of the aorta in patient with presumed Takayasu's aortitis. Cathet Cardiovasc Diagn 1996;38:406-9. 